\title{
Diffuse Cutaneous Systemic Sclerosis
}

National Cancer Institute

\section{Source}

National Cancer Institute. Diffuse Cutaneous Systemic Sclerosis. NCI Thesaurus. Code C116791.

A variant of systemic scleroderma characterized by sclerosis of the skin, Raynaud phenomenon, and organ involvement, including pulmonary fibrosis, renal disease, and gastrointestinal tract involvement. 